\title{
PERHITUNGAN BIAYA OPERASI DAN PERAWATAN PLTN SKALA BESAR DAN KECIL
}

\author{
Mochamad Nasrullah, Wiku Lulus Widodo \\ Pusat Kajian Sistem Energi Nuklir (PKSEN), BATAN \\ Jl. Kuningan Barat, Mampang Prapatan, Jakarta 12710 \\ Telp/Fax: (021) 5204243 Email: nasr@batan.go.id
}

\begin{tabular}{|c|c|c|}
\hline Diterima & Diterima dalam bentuk revisi & Disetujui \\
\hline 01 September 2015 & 13 Nopember 2015 & 20 Nopember 2015 \\
\hline
\end{tabular}

\begin{abstract}
ABSTRAK
PERHITUNGAN BIAYA OPERASI DAN PERAWATAN PLTN SKALA BESAR DAN

KECIL. Biaya pembangkit PLTN terdiri dari tiga komponen, yaitu biaya investasi, bahan bakar dan operasi perawatan (O \& M). Besarnya biaya OEM pada PLTN besar dan kecil tidaklah sama. Studi ini bertujuan untuk menghitung biaya OEM PLTN skala besar dan kecil dengan mempertimbangkan parameter teknis dan ekonomis yang diambil dari berbagai data sekunder dan sumber lainnya. Studi dilakukan menggunakan data dari PLTN jenis PWR dengan daya 1343 MWe untuk PLTN ukuran besar dan daya 90 MWe untuk PLTN ukuran kecil. Asumsi digunakan tingkat eskalasi sebesar 5\%, faktor kapasitas 90\%. Metodologi yang digunakan adalah menghitung dengan spreadsheet yang meliputi skala masing-masing komponen O\&M. Hasil perhitungan menunjukkan biaya $O$ \& $M$ jika dihitung dengan satuan juta US\$/tahun, maka biaya OEM PLTN 1343 MWe sebesar 99,21 juta US\$/tahun lebih mahal dari PLTN 90 MWe sebesar 45,13 juta US \$/tahun. Namun jika biaya O \& M PLTN 1343 MWe dihitung dengan satuan mills \$/kWh, maka hasilnya sebesar 9,37 lebih murah dibandingkan dengan PLTN 90 MWe yaitu sebesar 63,70 mills \$/kWh. Hal ini berarti semakin kecil ukuran kapasitas dayanya maka biaya operasi dan perawatannya semakin mahal. Penyebab perbedaan biaya operasi dan perawatan antara PLTN skala besar dan kecil, adalah kapasitas daya, faktor kapasitas, jumlah personal yang bekerja pada biaya administrasi umum pegawai dan manajemen, operasi pembangkit tahunan, biaya tenaga kerja offsite.
\end{abstract}

Kata kunci : Biaya operasi dan perawatan, PLTN, LEGECOST

\begin{abstract}
CALCULATION OF OPERATION AND MAINTENANCE COST FOR LARGE AND SMALL SCALE NPP. The generation cost of nuclear power plant consists of three components: investment costs, fuel cost operation and maintenance (O\&M) cost. O\&M costs in the large scale of NPP is different from small scale NPP. The objective of this study are to calculate the OEM cost of large NPP and small NPP by considering technical and economic parameters from secondary data and other references. This study uses 1343 MWe PWR data for large NPP and 90 MWe PWR for small NPP. The assumptions are 5\% escalation level and 90\% capacity factor. The methodology for calculation using spreadsheet with scaling methods for each OEM components. The results shows that the O EM cost if calculated in units of million US\$/year, the OEM cost of NPP 1343 MWe is US\$million 99.21/ year which is more expensive than the OEM cost of NPP 90 Mwe which is only US\$million 45.13/ year. But if the cost of OEM 1343 MWe nuclear power plant unit is calculated in units of mills $\$ / k W h$, the result shows that the O\&M cost is 9.37 mills $\$ / k W h$ which is less than the 90 MWe NPP which reaches $\$ 63.70$ mills $/ k W h$. The conclusion is lower NPP capacity has higher OEM cost. Different OEM cost is caused by power capacity, capacity factor, the amount of worker on site staff, the annual net generation and the offsite technical support.
\end{abstract}

Keywords: Operation and maintenance cost, NPP, LEGECOST 


\section{PENDAHULUAN}

Perhitungan ekonomi sangat diperlukan untuk mengetahui obyektifitas dari biaya Pembangkit Listrik Tenaga Nuklir (PLTN) dan dalam menentukan harga tarif listrik (levelized tariff). Model perhitungan yang digunakan dalam menghitung keekonomian PLTN salah satunya adalah model yang dikeluarkan oleh IAEA (International Atomic Energy Agency) dalam bentuk spreadsheet yaitu LEGECOST (Levelized Generation Cost)[1].

Perhitungan biaya pembangkit listrik terdiri dari tiga komponen, yaitu biaya investasi, bahan bakar serta operasi dan perawatan, dimana dalam studi ini akan di fokuskan pada biaya operasi dan perawatan (Operation and Maintenance, O\&M). Biaya O\&M merupakan biaya yang dibutuhkan untuk menjalankan operasi rutin PLTN dan besarnya bergantung pada teknologi dan kapasitas daya yang terpasang. Biaya O\&M dibedakan menjadi dua, yaitu biaya tidak tetap dan biaya tetap. Biaya operasi dan perawatan tidak tetap ini berubah mengikuti inflasi, eskalasi, upah tenaga kerja, material bahan yang digunakan. Sedangkan biaya tetap merupakan biaya operasional rutin yang antara lain meliputi biaya pegawai, property tax, plant insurance, dan life-cycle maintenance[2].

Biaya O \& M pada PLTN yang mempunyai perbedaan ukuran kapasitas daya, akan menghasilkan biaya yang berbeda pula. Kesulitan terjadi pada saat menghitung biaya $\mathrm{O} \&$ M pada PLTN yang tidak mempunyai data lengkap dan berbeda ukuran. Biaya operasi dan perawatan pada PLTN dapat dihitung dengan menggunakan perhitungan skala pada biaya operasi dan perawatan.

Studi ini bertujuan untuk menghitung biaya O\&M PLTN skala besar dan kecil dengan mempertimbangkan parameter teknis dan ekonomis yang diambil dari berbagai data sekunder dan sumber lainnya. Ruang lingkup studi ini adalah PLTN jenis PWR berkapasitas daya sebesar $1343 \mathrm{MWe}^{[3]}$ yang akan digunakan sebagai dasar menghitung pada skala yang lebih kecil yaitu PLTN jenis PWR 90 MWe[3]. Diharapkan dengan mengetahui perhitungan biaya O\&M PLTN skala besar dan kecil, maka perhitungan biaya keekonomian dari komponen biaya O \& M PLTN kecil sangat terbatas sehingga dalam studi ini akan dilakukan scale down dari PLTN skala besar untuk mendapatkan biaya O\&M untuk PLTN kecil yang lebih riil.

\section{METODOLOGI}

Metodologi yang digunakan dalam menghitung biaya O\&M PLTN besar kecil adalah dengan menghitung komponen biaya O\&M seperti biaya administrasi umum pegawai dan manajemen, biaya rutin dan komponen perawatan, biaya tenaga kerja operator teknisi, biaya pensiun dan manfaat, biaya regulasi nuklir dan biaya asuransi pembangkit serta biaya umum dan administrasi lain menggunakan skala komponennya masing-masing dengan bantuan spreadsheet. Secara lengkap metode perhitungan adalah sebagai berikut:

\subsection{Biaya Administrasi Umum Pegawai dan Manajemen (Onsite Staff)}

Untuk menghitung komponen biaya O\&M PLTN pada onsite staff, pertama adalah dengan cara menghitung jumlah tenaga kerja, dengan rumus perhitungan Onsite Staff sebagai berikut ${ }^{[4]}$ :

$$
\mathrm{OS}=\frac{\mathrm{TKR} \times(\mathbf{P} \times \mathbf{C F}) 0.5 \times(\mathrm{NU}) 0.6}{\mathrm{PR}}
$$

Dimana:

$$
\begin{aligned}
& \text { OS = Jumlah Tenaga Kerja On Site } \\
& \text { TKR = Jumlah Tenaga Kerja Referensi } \\
& \mathrm{P} \quad=\text { Daya PLTN }
\end{aligned}
$$




$$
\begin{aligned}
\mathrm{CF} & =\text { Faktor Kapasitas } \\
\mathrm{NU} & =\text { Jumlah Unit } \\
\mathrm{PR} & =\text { Daya PLTN Referensi }
\end{aligned}
$$

Perhitungan Onsite Staff adalah kapasitas daya PLTN dikalikan dengan faktor kapasitas dikalikan jumlah unit. Selanjutnya jumlah tenaga kerja dikalikan dengan upah tenaga kerja sehingga dihasilkan biaya onsite staff.

\subsection{Biaya Rutin dan Komponen Perawatan (BRKP)}

Perhitungan komponen biaya O\&M PLTN pada maintenance materials adalah menggunakan rumus maintenance materials sebagai berikut ${ }^{[4]}$ :

$$
\mathrm{BRKP}=\frac{\mathrm{FPR} \times \mathrm{RBO} \times(\mathrm{P} \times \mathrm{CF})^{0.5} \times(\mathrm{NU}){ }^{0.6}}{\mathrm{PR}}
$$

Dimana:

$$
\begin{array}{ll}
\text { BRKP } & =\text { Biaya Rutin dan Komponen Perawatan } \\
\text { FPR } & =\text { Faktor Pengali } \\
\text { RBO } & =\text { Rata-rata biaya Onsite Staff } \\
\mathrm{P} & =\text { Daya PLTN } \\
\mathrm{CF} & =\text { Faktor Kapasitas } \\
\mathrm{NU} & =\text { Jumlah Unit } \\
\mathrm{PR} & =\text { Daya PLTN Referensi }
\end{array}
$$

\subsection{Biaya Penyimpanan (Supplies and Expenses) (BP)}

Sedangkan perhitungan biaya penyimpnanan (Supplies and Expenses) komponen biaya operasi dan perawatan PLTN adalah dengan menggunakan rumus sebagai berikut ${ }^{[4]}$ :

$$
\mathrm{BP}=\frac{(\mathrm{TFC}) \times(\mathrm{P} \times \mathrm{CF}) 0.5 \times(\mathrm{NU})}{\mathrm{PR}}^{0.6}
$$

Dimana:

$$
\begin{aligned}
& \mathrm{BP}=\text { Biaya Penyimpanan } \\
& \mathrm{TFC}=\text { Total Fixed Cost } \\
& \mathrm{P}=\text { Daya PLTN } \\
& \mathrm{CF}=\text { Faktor Kapasitas } \\
& \mathrm{NU}=\text { Jumlah Unit } \\
& \mathrm{PR}=\text { Daya PLTN Referensi }
\end{aligned}
$$

\subsection{Biaya Tenaga Kerja Operator Teknisi (Offsite Staff)}

Perhitungan pada komponen biaya tenaga kerja operator teknisi (Offsite Technical Support) dalam biaya O\&M PLTN atau disebut dengan labor cost (tenaga kerja operator/teknisi dan keamanan). Untuk menghitung jumlah offsite staff adalah dengan menghitung jumlah unit dikalikan kapasitas daya dikalikan faktor kapasitasnya. Rumus yang digunakan untuk menghitung jumlah Offsite Staff adalah [4]:

$$
\text { OFS }=\frac{\text { FP }+(\text { FPOF } \times \text { NU }) \times(P \times C F)^{0.5}}{P R}
$$

Dimana:

$$
\begin{aligned}
& \mathrm{OFS}=\text { Jumlah Tenaga Kerja Offsite } \\
& \mathrm{FP}=\text { Faktor Pengali }
\end{aligned}
$$




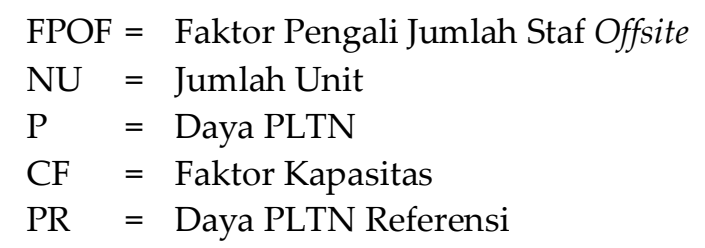

2.5. Biaya Pensiun dan Manfaat, Biaya Regulasi Nuklir dan Biaya Asuransi Pembangkit serta Biaya Umum dan Administrasi lain

Perhitungan komponen biaya ini dilakukan dengan cara memasukkan data biaya pensiun dan manfaat, biaya regulasi nuklir dan biaya asuransi pembangkit serta administrasi lain dan biaya umum dalam komponen biaya operasi dan perawatan PLTN ${ }^{[4]}$.

\section{DATA DAN ASUMSI}

\subsection{Data Parameter Biaya Operasi dan Perawatan PLTN}

Parameter biaya operasi dan perawatan PLTN yang digunakan dalam perhitungan adalah sebagai berikut:

Tabel 1. Data Parameter Biaya Operasi dan Perawatan PLTN

\begin{tabular}{|c|c|c|c|}
\hline Parameter & Satuan & Nilai & Nilai \\
\hline Kapasitas Daya & MWe & 1343 & 90 \\
\hline Jumlah Unit Pembangkit & unit & 1 & 1 \\
\hline Faktor Kapasitas [3] & $\%$ & 90 & 90 \\
\hline \multicolumn{4}{|l|}{ Tingkat Eskalasi } \\
\hline $\begin{array}{l}\text { - Upah dan gaji, bahan dan perlengkapan, } \\
\text { biaya regulasi dan asuransi nuklir }\end{array}$ & $\%$ & 5 & 5 \\
\hline Rata-rata biaya Onsite Staff & \$/tahun & $36000^{[4]}$ & 36000 \\
\hline Rata-rata biaya Offsite Staff & $\$ /$ tahun & $51000^{[4]}$ & 51000 \\
\hline Administrasi umum dan manajemen & $\%$ & 15 & 15 \\
\hline Operasi pembangkit tahunan, ${ }^{[4]}$ & juta $\mathrm{kWh}$ & 10588 & 710 \\
\hline
\end{tabular}

\subsection{Biaya Operasi dan Perawatan}

Biaya O\&M merupakan biaya yang dibutuhkan untuk menjalankan operasi rutin PLTN. Biaya O\&M dibedakan menjadi dua kategori, yaitu biaya tidak tetap O\&M dan biaya tetap O\&M. Biaya tetap O\&M artinya walaupun tidak ada produksi energi yang dihasilkan biaya tersebut tetap ada ${ }^{[9]}$, dan merupakan biaya operasional rutin yang meliputi biaya pegawai, property tax, plant insurance, dan life-cycle maintenance. Biaya tidak tetap O\&M adalah biaya yang memiliki pengaruh langsung pada energi yang dihasilkan dari pembangkit dan besarnya tergantung pada output produksi energi. Biaya ini mencakup biaya bahan bakar, consumables materials, pemeliharaan langsung unit pembangkit, pemeliharaan gedung pembangkit, dan pemeliharaan oleh outsourcing. Biaya tidak tetap O\&M dan biaya tetap O\&M umumnya diukur dalam satuan US\$/tahun atau US\$/MWh ${ }^{[5]}$.

\subsubsection{Biaya Administrasi Umum Pegawai dan Manajemen (Onsite Staff)}

Biaya Onsite Staff atau disebut juga biaya administrasi umum pegawai dan manajemen, merupakan biaya yang dialokasikan untuk membayar biaya gaji manajemen, yang terdiri dari plant manager office, operation, maintenance, dan technical support. Termasuk general manager, sekretaris, manajer, asisten manajer, tenaga ahli dan tenaga administrasi. Biaya ini merupakan bagian dari biaya O\&M, biaya yang memperhitungkan pendapatan seseorang pada tiap bulan atau tahunnya berdasarkan pekerjaan yang dilakukan. Secara 
rinci biaya onsite staff dapat dilihat pada Tabel 2.

Tabel 2. Estimasi Gaji Tahunan dan Onsite Staff (US \$/tahun)

\begin{tabular}{|c|c|c|c|c|c|}
\hline \multirow{2}{*}{ Jenis Pekerjaan } & \multirow[t]{2}{*}{ Gaji ${ }^{[6]}$} & \multirow{2}{*}{\multicolumn{2}{|c|}{$\begin{array}{l}\text { Total Tenaga Kerja } \\
1343 \text { MWe } 90 \text { MWe }\end{array}$}} & \multicolumn{2}{|c|}{ Total Gaji } \\
\hline & & & & 1343 MWe & 90 MWe \\
\hline \multicolumn{6}{|l|}{ Office } \\
\hline Manajer Pembangkit & 174100 & 1 & 1 & 174100 & 174100 \\
\hline Assistant Manager & 121200 & 1 & - & 121200 & 0 \\
\hline Humas & 77000 & 2 & 1 & 154000 & 77000 \\
\hline Pengendali Lingkungan & 77000 & 3 & 1 & 231000 & 77000 \\
\hline Jaminan Mutu & 63700 & 6 & 2 & 382200 & 127400 \\
\hline Pelatihan & 84200 & 50 & 13 & 4210000 & 1094600 \\
\hline Safety and fire protect & 71400 & 7 & 2 & 499800 & 142800 \\
\hline Jasa Administrasi & 46200 & 84 & 22 & 3880800 & 1016400 \\
\hline Pemadam Kebakaran & 71400 & 28 & 7 & 1999200 & 499800 \\
\hline Keamanan & 41600 & 132 & 34 & 5491200 & 1414400 \\
\hline Sub total & 827800 & 314 & 83 & 259929200 & 58647800 \\
\hline \multicolumn{6}{|l|}{ Operation } \\
\hline Supervisi & 89400 & 4 & 1 & 357600 & 89400 \\
\hline Shift operations & 75000 & 108 & 28 & 8100000 & 2100000 \\
\hline Engineering & 75000 & 21 & 5 & 1575000 & 375000 \\
\hline Sub Total & 239400 & 133 & 34 & 31840200 & 8139600 \\
\hline \multicolumn{6}{|l|}{ Perawatan } \\
\hline Supervisi & 82900 & 7 & 2 & 580300 & 165800 \\
\hline Crafts & 58900 & 147 & 38 & 8658300 & 2238200 \\
\hline Annualized peak & 58900 & 58 & 15 & 3416200 & 883500 \\
\hline Engineering & 75000 & 13 & 3 & 975000 & 225000 \\
\hline Quality Control & 63700 & 7 & 2 & 445900 & 127400 \\
\hline Storekeepers & 42000 & 9 & 2 & 378000 & 84000 \\
\hline Sub total & 381400 & 241 & 62 & 91917400 & 23646800 \\
\hline \multicolumn{6}{|l|}{ Technical Support } \\
\hline Reactor Engineering & 89400 & 5 & 1 & 447000 & 89400 \\
\hline Radiochem and Water Chemical & 82900 & 13 & 3 & 1077700 & 248700 \\
\hline Engineering & 76500 & 31 & 8 & 2371500 & 612000 \\
\hline Technicians & 62200 & 63 & 16 & 3918600 & 995200 \\
\hline Health Physics & 64000 & 38 & 10 & 2432000 & 640000 \\
\hline Sub total & 375000 & 150 & 38 & 56250000 & 14250000 \\
\hline Total Onsite staff & 1823600 & 839 & 217 & 439936800 & 104684200 \\
\hline
\end{tabular}

Catatan : Total gaji onsite tahunan 30,20 juta US \$, rata-rata gaji tahunan US \$ 36.000 [8]

\subsubsection{Biaya Operasi Rutin dan Perawatan}

Biaya operasi rutin dan perawatan merupakan biaya yang dialokasikan untuk melaksanakan pemeliharaan aset. Estimasi biaya komponen perawatan berdasarkan referensi yang berhubungan dengan material ditunjukkan dalam Tabel 3 yang terbagi dalam komponen tetap dan tidak tetap. Total pengeluaran tahunan dari maintenance materials diestimasi untuk menyamakan biaya pengeluaran tahunan maintenance staff 
dengan faktor kapasitas 90\%. Di asumsikan estimasi komponen tetap 0,75 dan komponen tidak tetap 0,25 pada capacity factor $90 \%$. Biaya maintenance material untuk komponen tetap dan tidak tetap PLTN 1343 MWe sebesar 5,72 juta US\$/tahun dan 1,90 juta US\$/tahun. Hasil perhitungan biaya maintenance material untuk komponen tetap dan tidak tetap PLTN 90 MWe sebesar 1,48 juta US\$/tahun dan 0,47 juta US\$/tahun.

Tabel 3. Biaya Operasi Rutin dan Komponen Perawatan (\$juta/tahun)

\begin{tabular}{llcc}
\hline Biaya & Nilai & PLTN 1343 MWe & PLTN 90 MWe \\
\hline Komponen Tetap & 0,75 & 5,72 & 1,48 \\
Komponen Tidak Tetap & 0,25 & 1,90 & 0,47 \\
\hline Total & 1,00 & 7,62 & 1,95 \\
\hline
\end{tabular}

\subsubsection{Biaya Penyimpanan (Supplies and Expenses)}

Supplies and Expenses adalah biaya yang dialokasikan untuk biaya penyimpanan bahan bakar bekas sementara (onsite), penyimpanan bahan bakar bekas lestari dan biaya dekomisioning. Biaya dekomisioning dialokasikan setiap tahun selama masa operasi PLTN sampai batas umur PLTN ${ }^{[2]}$. Biaya penyimpanan (Supplies and Expenses) ini terdiri atas biaya tetap dan tetap. Biaya tetap terdiri atas miscellaneous supplies, makeup materials and chemicals, steam from other sources, rents, training, data processing, radioactive waste management dan non radioactive waste management. Total biaya tetap dan biaya tidak tetap PLTN 1343 MWe sebesar 13,81 juta US \$/tahun dan 2,47 juta US \$/tahun. Sedangkan Total biaya tetap dan biaya tidak tetap PLTN 90 MWe sebesar 3,58 juta US \$/tahun dan 0,17 juta US \$/tahun. Secara rinci estimasi annual costs supplies dan expenses dapat dilihat pada Tabel 4.

Tabel 4. Supplies dan Expenses PLTN (US \$juta/tahun)

\begin{tabular}{lcc}
\hline \multicolumn{1}{c}{ Keterangan } & $\begin{array}{c}\text { PLTN } \\
\text { 1343 } \mathbf{~ M W e ~}\end{array}$ & $\begin{array}{c}\text { PLTN } \\
\text { 90 } \mathbf{M W e}\end{array}$ \\
\hline Biaya tetap & 13,81 & 3,58 \\
Biaya tidak tetap & 2,47 & 0,17 \\
\hline Total biaya Supplies dan Expenses & 16,28 & 3,74 \\
\hline
\end{tabular}

\subsubsection{Biaya Tenaga Kerja Operator Teknisi (Labor Cost)}

Biaya tenaga kerja operator teknisi atau labor cost merupakan biaya yang dialokasikan untuk membayar biaya pegawai atau operator selain yang masuk kelompok biaya administrasi dan umum, termasuk bonus, asuransi kesehatan dan pajak penghasilan ${ }^{[2]}$. Biaya pegawai untuk labor cost dapat dilihat pada Tabel 5. Jumlah staf offsite pada PLTN dengan ukuran yang berbeda akan berbeda pula, seperti jumlah personal tenaga kerja operator teknisi untuk PLTN 1343 MWe sebesar 150 orang dan untuk PLTN ukuran 90 MWe 114 orang. Total biaya tahunan untuk tenaga kerja operator teknisi masing-masing sebesar 13.056.150 US \$ untuk PLTN 1343 MWe dan 9.961.092 US \$ untuk PLTN 90 MWe. Rincian biaya pegawai untuk tenaga kerja operator teknisi dapat dilihat pada Tabel 5. 
Tabel 5. Biaya Tenaga Kerja Operator Teknisi (Labor Cost)

\begin{tabular}{cccc}
\hline Keterangan & Satuan & PLTN 1343 MWe & PLTN 90 MWe \\
\hline Jumlah staff & orang & 150 & 114 \\
Rata-rata gaji tahunan & US \$ & 51.000 & 51.000 \\
Total Gaji tahunan & US \$ & 7.650 .000 & 5.791 .969 \\
Daftar pajak dan asuransi $^{a}$ & US \$ & 765.000 & 579.197 \\
Overhead $^{b}$ & US \$ & 4.590 .000 & 3.475 .181 \\
\hline Total Biaya Tahunan Operator Teknisi $^{2}$ & US \$ & 13.056 .150 & 9.897 .460 \\
\hline
\end{tabular}

Keterangan: ${ }^{a} 10 \%$ of total salaries, ${ }^{b} 60 \%$ of total salaries

\subsubsection{Biaya Pensiun dan Manfaat (Pensions and Benefits)}

Biaya operasi dan perawatan dari biaya pembangkit berasal dari jumlah biaya onsite staff, maintenance materials, supplies and expenses, offsite technical support PLTN 1343 MWe sebesar 67,17 juta US\$ dan PLTN 90 MWe sebesar 23,40 juta US\$. Biaya pensions and benefits diasumsikan $15 \%$ dari total biaya operasi dan perawatan dari power generation cost PLTN 1343 MWe sebesar 9,11 juta US\$ dan PLTN 90 MWe sebesar 3,51 juta US\$.

\subsubsection{Biaya Regulasi Nuklir (Nuclear Regulatory Fees)}

Biaya regulasi nuklir adalah biaya yang dikeluarkan dalam proses perijinan PLTN, diasumsikan berdasarkan referensi estimasi biaya regulasi nuklir tahunan untuk PLTN tiap unit sebesar 1.250.000 US \$/tahun ${ }^{[4]}$.

\subsubsection{Biaya Asuransi Pembangkit (Nuclear Insurance Premium)}

Asuransi pembangkit merupakan biaya yang dialokasikan untuk membayar asuransi PLTN yang meliputi reaktor nuklir, steam generator, turbin dan peralatan lain dalam sistem PLTN. Biaya asuransi pembangkit terdiri dari public liability dan plant property damage yang totalnya sebesar 6.300 .000 US\$. Biaya public liability sebesar 600.000 US\$[4] berasal dari perkalian biaya commercial 160.000 .000 US\$ dengan asumsi penetapan $0,375 \%$ dari biaya commercial.

\subsubsection{Biaya Variabel OEM}

Besarnya biaya variabel OEM terdapat pada komponen maintenance materials dan supplies and expenses. Biaya variabel ini terdiri dari biaya-biaya untuk pemeliharaan langsung unit pembangkit, pemeliharaan gedung pembangkit, dan pemeliharaan oleh outsourcing. Total biaya variabel PLTN 1343 MWe sebesar 4,38 juta US\$ dan PLTN 90 MWe sebesar 0,63 juta US\$.

\section{HASIL DAN PEMBAHASAN}

Biaya operasi dan perawatan PLTN 1343 MWe dan 90 MWe merupakan penjumlahan biaya komponen O\&M seperti biaya administrasi umum pegawai dan manajemen, komponen perawatan, biaya penyimpanan, biaya tenaga kerja operator teknisi, pensiun dan manfaat, biaya regulasi nuklir, biaya asuransi pembangkit, biaya umum dan administrasi lain. Hasil perhitungan operasi dan perawatan antara PLTN ditunjukkan pada Tabel 6, pada biaya on-sites staff pada PLTN 1343 MWe sebesar 30,20 juta US\$ dan PLTN 90 MWe sebesar 7,81 juta US\$.

Biaya Operasi dan Perawatan PLTN yang terdapat komponen biaya tetap dan tidak tetap (variable). Berdasarkan Tabel 6 hasil perhitungan studi biaya operasi dan perawatan PLTN 1343 MWe sebesar 9,37 mills $\$ / \mathrm{kWh}$ dan PLTN 90 MWe sebesar 63,70 mills $\$ / \mathrm{kWh}$. Jika dibandingkan dengan hasil referensi seperti dilihat pada Tabel 7, ternyata hasilnya menunjukkan biaya O\&M APR 1400 dari Korea Selatan sebesar 9 mills $\$ / k W h$, sedangkan 
hasil perhitungan studi sebesar 9,37 mills $\$ / \mathrm{kWh}$, ini menunjukkan selisih 0,37 mills $\$ / \mathrm{kWh}$. Artinya dengan selisih tidak terlalu besar, menunjukkan validitas perhitungannya sudah baik.

Hasil perhitungan biaya operasi dan perawatan PLTN menunjukkan biaya yang berbeda pada masing-masing komponen total non-fuel operasi dan perawatan. Total operasi dan perawatan PLTN 1343 MWe sebesar 99,21/tahun juta US\$, sedangkan operasi dan perawatan PLTN 90 MWe sebesar 45,13 juta US \$/tahun, ini menunjukkan biaya operasi dan perawatan PLTN 1343 MWe lebih mahal dibandingkan dengan PLTN 90 MWe, namun jika dihitung dengan satuan mills $\$ / \mathrm{kWh}$, maka biaya operasi dan perawatan yang sudah memperhitungkan biaya administrasi dan umum PLTN 1343 MWe sebesar 9,37 mills $\$ / \mathrm{kWh}$ dan biaya operasi dan perawatan PLTN 90 MWe sebesar 63,60 mills $\$ / \mathrm{kWh}$.

Tabel 6. Hasil Perhitungan Biaya Operasi dan Perawatan (juta US\$)

\begin{tabular}{|c|c|c|}
\hline+2 & PLTN 1343 MWe & PLTN 90 MWe \\
\hline On sites Staff & 30.20 & 7.81 \\
\hline \multicolumn{3}{|l|}{ Komponen Perawatan } \\
\hline Tetap & 5.72 & 1.48 \\
\hline Tidak tetap (Variabel) & 1.91 & 0.47 \\
\hline Subtotal & 7.623 & 1.95 \\
\hline \multicolumn{3}{|l|}{ Supplies and expenses } \\
\hline Tetap & 13.81184 & 3.58 \\
\hline Tidak tetap (Variabel) & 2.47 & 0.17 \\
\hline Subtotal & 16.28 & 3.74 \\
\hline biaya tenaga kerja operator teknisi & 13.06 & 9.90 \\
\hline \multicolumn{3}{|l|}{ Subtotal, $\mathrm{O} \& \mathrm{M}$ biaya pembangkitan } \\
\hline Tetap & 62.79 & 22.76 \\
\hline Tidak tetap (Variabel) & 4.38 & 0.63 \\
\hline Subtotal & 67.17 & 23.40 \\
\hline \multicolumn{3}{|l|}{ Biaya Administrasi Umum dan Manajemen } \\
\hline Pensiun dan Manfaat & 10.07 & 3.51 \\
\hline Fee Regulasi Nuklir & 1.25 & 1.25 \\
\hline Kewajiban Asuransi & 0.60 & 0.60 \\
\hline Asuransi Kepemilikan & 4.10 & 4.10 \\
\hline Asuransi Replacement power & 1.60 & 1.60 \\
\hline Biaya Administrasi Umum dan Manajemen & 10.04 & 10.04 \\
\hline Subtotal & 27.66 & 21.10 \\
\hline \multicolumn{3}{|l|}{ Total O \& M Costs (\$million/year) } \\
\hline Tetap & 94.83 & 44.49 \\
\hline Tidak tetap (Variabel) & 4.38 & 0.63 \\
\hline Total non fuel OEM & 99.21 & 45.13 \\
\hline Administrasi Umum dan Manajemen (mills/kWh) & 9.37 & 63.60 \\
\hline $\begin{array}{l}\text { Tanpa Administrasi Umum dan Manajemen } \\
\text { (mills/kWh) }\end{array}$ & 6.34 & 32.97 \\
\hline
\end{tabular}

Sedangkan biaya operasi dan perawatan PLTN tanpa administrasi umum dan manajemen untuk PLTN 1343 MWe sebesar 6,34 mills \$/kWh dan biaya operasi dan 
perawatan PLTN 90 MWe sebesar 32,97 mills $\$ / \mathrm{kWh}$. Artinya biaya operasi dan perawatan PLTN dengan kapasitas daya lebih besar akan lebih murah dibandingkan kapasitas daya yang lebih kecil.

Tabel 7. Perbandingan Biaya Operasi dan Perawatan PLTN

\begin{tabular}{lcc}
\hline Reaktor & Daya (MWe) & Biaya O \& M (mills \$/kWh) \\
\hline Referensi APR 1400 & 1343 & 9,00 \\
Hasil Perhitungan & 1343 & 9,37 \\
Referensi EPIC SMR LEAD/2[7] & 300 & 25,49 \\
Hasil Perhitungan & 90 & 63,60 \\
\hline
\end{tabular}

Untuk lebih memperkuat hasil analisis pembahasan diperlukan hasil referensi, ini ditunjukkan pada Tabel 7 yang menunjukkan hasil perhitungan selain PLTN 1343 MWe dan PLTN 90 MWe, yaitu PLTN 300 MWe (EPIC SMR LEAD/2) yang diambil dari referensi, menunjukkan biaya O\&M sebesar 25,49 mills $\$ / \mathrm{kWh}$, jika semakin kecil ukuran kapasitas dayanya (90 MWe), hasil perhitungan menunjukkan biaya O\&M sebesar 63,60 mills $\$ / \mathrm{kWh}$. Hasil perhitungan biaya operasi dan perawatan PLTN berbeda karena perbedaan dari kapasitas daya, faktor kapasitas, jumlah personil yang bekerja pada biaya administrasi umum pegawai dan manajemen, operasi pembangkit tahunan, biaya tenaga kerja operator teknisi dan keamanan, hal ini ditunjukkan pada Tabel 6.

\section{KESIMPULAN}

Jika dihitung dengan satuan juta US \$/tahun biaya O\&M PLTN 1343 Mwe menunjukkan sebesar 99,21 juta US \$ /tahun lebih mahal dari PLTN 90 MWe sebesar 45,13 juta US \$ /tahun. Namun jika biaya O\&M PLTN 1343 MWe dihitung dengan satuan mills $\$ / \mathrm{kWh}$, hasilnya lebih murah sebesar 9,37 mills $\$ / \mathrm{kWh}$ dibandingkan dengan PLTN 90 MWe yaitu sebesar 63,70 mills $\$ / \mathrm{kWh}$. Hal ini berarti semakin kecil ukuran kapasitas daya PLTN biaya operasi dan perawatannya akan semakin mahal. Penyebab perbedaan biaya operasi dan perawatan antara PLTN skala besar dan kecil, adalah kapasitas daya, faktor kapasitas, jumlah personal yang bekerja pada biaya administrasi umum pegawai dan manajemen, operasi pembangkit tahunan, biaya tenaga kerja operator teknisi dan keamanan.

\section{DAFTAR PUSTAKA}

[1]. NASRULLAH, M., "Perhitungan Ekonomi dan Pendanaan PLTN SMR 100 MWe", Prosiding Seminar Nasional Teknologi Energi Nuklir, Pontianak, Kalbar, Juni 2014 Jakarta, Oktober 2014.

[2]. PT. PLN (Persero) Litbang., "Studi Ekonomi, Pendanaan dan Struktur Owner Dalam Rangka Rencana Persiapan Pembangunan PLTN Pertama di Indonesia", PLN, Jakarta, 2006.

[3]. NEA, "Current Status, Technical Feasibility and Economics of Small Nuclear Reactors", Nuclear Energy Agency, June 2011.

[4]. H I. BOWERS, et al., "Cost Estimating Relationships For Nuclear Power Plant Operation And Maintenance", Oak Ridge National Laboratory, November 1987.

[5]. NASRULLAH, M., "Studi Perbandingan Harga dan Tarif Listrik PLTN Dari Berbagai Negara", Pusat Pengembangan Energi Nuklir, Badan Tenaga Nuklir Nasional, Jakarta, 2009.

[6]. GIF EMWG - Cost Estimating Guidelines For Generation Iv Nuclear Energy Systems, 2007 
[7]. EPIC, "Small Modular Reactors - Key to Future Nuclear Power Generation in the U.S", 2011.

[8]. _ "Salary Report", http://www.payscale.com/research/US/Job=Nuclear. Diakses tanggal 12 Jan 2016.

[9]. MARSH, W. D., "Economics of Electric Utility Power Generation", New York: Clarendon Press-Oxford, University Press, 1980. 